\title{
Answer letter concerning "The effect of new preoperative preparation method compared to conventional method in complex acetabular fractures: minimum 2-year follow-up"
}

\author{
Pengfei Wang ${ }^{1} \cdot$ Yan Zhuang ${ }^{1} \cdot$ Kun Zhang $^{1}$ \\ Published online: 23 January 2021 \\ (c) The Author(s), under exclusive licence to Springer-Verlag GmbH, DE part of Springer Nature 2021
}

We appreciate the opportunity to respond to the comment on the article "The effect of new preoperative preparation method compared to conventional method in complex acetabular fractures: minimum 2-year follow-up" by Dr. Tomonori Shigemura. Dr. Shigemura brings up a pertinent point in his response.

Based on the results of the study, we concluded that the new preoperative preparation method, developed using a 3D-printed model, is more effective and safer than the conventional method in the surgical treatment of complex acetabular fractures, suggesting that 3D-printed models may lead to a better understanding of fracture patterns and surgical planning for younger surgeons [1].

In our study, the results regarding the radiographic grades obtained for the new method group (group 1) and the traditional method group (group 2) interested Dr. Tomonori Shigemura. Dr. Shigemura indicated that this study produced insufficient evidence of the effectiveness of this method.

The results from our study showed that there was no significant difference in the radiographic grades between the two groups. However, $85.4 \%$ of the patients were rated excellent or good grade in group 1 vs $78.8 \%$ in group 2, indicating an overall trend of better grades in group 1 . This seems to be because the 3D-printing technique and the precontoured plate facilitated fracture reduction in complex acetabular fractures, similar to the results from a previous retrospective study conducted by Dr. Chun-Chi Hung [2]. Furthermore, Maini conducted a prospective randomized case control study and similarly found that the postoperative

Kun Zhang

13759994007@163.com

Pengfei Wang

13759994007@163.com

1 Department of Orthopedics and Traumatology, Xi'an Honghui Hospital, Xi'an Jiaotong University Health Science Center, Xi'an, China reduction results on X-ray did not meet the level of significance $(p=0.243)$ [3]. Matta indicated that the rate of anatomic reduction decreases with increased fracture complexity, patient age, and time to fracture fixation [4]. In our study, the mean age in group 1 was greater than that in group 2, and the time from injury to surgery was longer in group 1 than in group 2. These two factors might have influenced the final results.

We hope that our study and the comment from Dr. Tomonori Shigemura will provide a reference for future study on this topic.

\section{References}

1. Wang P, Kandemir U, Zhang B, Fei C, Zhuang Y, Zhang K (2020) The effect of new preoperative preparation method compared to conventional method in complex acetabular fractures: minimum 2-year follow-up. Arch Orthop Trauma Surg. https:// doi.org/10.1007/s00402-020-03472-w

2. Hung C-C, Li Y-T, Chou Y-C, Chen J-E, Chia-Chun Wu, Shen $\mathrm{H}-\mathrm{C}$, Yeh T-T (2019) Conventional plate fixation method versus pre-operative virtual simulation and three-dimensional printingassisted contoured plate fixation method in the treatment of anterior pelvic ring fracture. Int Orthop 43(2):425-431. https://doi. org/10.1007/s00264-018-3963-2

3. Maini L, Sharma A, Jha S, Sharma A, Tiwari A (2018) Threedimensional printing and patient-specific pre-contoured plate: future of acetabulum fracture fixation? Eur J Trauma Emerg Surg Off Publ Eur Trauma Soc 44(2):215-224. https://doi.org/10.1007/ s00068-016-0738-6

4. Joel MMATTA (1996) Fractures of the acetabulum: accuracy of reduction and clinical results in patients managed operatively within three weeks after the injury. J Bone Jt Surg Am 78(11):1632-1645

Publisher's Note Springer Nature remains neutral with regard to jurisdictional claims in published maps and institutional affiliations. 